\title{
Superplastic Bulging of Fine-Grained Zirconia
}

\author{
Xin Wu* and I-Wei Chen* \\ Department of Materials Science and Engineering, University of Michigan, \\ Ann Arbor, Michigan 48109-2136
}

\begin{abstract}
A tetragonal zirconia containing $2 \mathrm{~mol} \% \mathrm{Y}_{2} \mathrm{O}_{3}$, with $0.3 \mathrm{~mol} \%$ $\mathrm{CuO}$ addition as a grain-boundary phase, was superplastically stretched at $1150^{\circ} \mathrm{C}$ using a hemispherical punch. Mechanical analyses were performed to establish that a biaxial tensile stress/strain state was achieved in the process with a maximal strain of 0.5 in the thinned hemispherical shell. The material was damage tolerant up to a critical strain rate, approximately $10^{-3} \mathrm{~s}^{-1}$. [Key words: mechanical properties, zirconia: yttria stabilized tetragonal polycrystals, grain boundaries, plasticity.]
\end{abstract}

\section{Introduction}

Quperplastic forming of zirconia ceramics by forging, ${ }^{1,2} \mathrm{di}$ rect and inverse extrusion, ${ }^{3}$ and bar and sheet bending ${ }^{4}$ has been reported by several groups. None of the above attempts was conducted under a biaxial tension. In the shellforming experiment reported by Carry and Mocellin, ${ }^{3}$ although a hemispherical shape was obtained, it nevertheless involved mostly balanced compression and tension (i.e., pure shear). Even the uniaxial tensile tests, widely reported by many investigators, ${ }^{5-7}$ are not as severe as the biaxial tensile tests for the purpose of assessing formability. ${ }^{8}$ In addition, the typical forming time was long (from $30 \mathrm{~min}$ to several hours), and the forming temperature was high (between $1300^{\circ}$ and $1500^{\circ} \mathrm{C}$ ). For technological applications, it would be much more desirable if biaxial forming at a higher speed and a lower temperature could be practiced. This would permit more shaping flexibility, higher productivity, lower energy consumption, and less capital and tooling costs. The work reported here is a feasibility study of biaxial forming using tetragonal zirconia polycrystals (TZP) expressly processed for low-temperature superplasticity.

\section{Experimental Procedures}

The TZP selected in this study has a base composition of $98 \mathrm{~mol} \% \mathrm{ZrO}_{2}$ and $2 \mathrm{~mol} \% \mathrm{Y}_{2} \mathrm{O}_{3}$, which is a single-phase (tetragonal) fine-grain ceramic. To this composition, $0.3 \mathrm{~mol} \%$ $\mathrm{CuO}$ was added to form a grain-boundary phase, which has a eutectic temperature estimated as $1130^{\circ} \mathrm{C}$. The powders were colloidally processed and sintered to full density at $1250^{\circ} \mathrm{C}$. The grain size, taken as the linear intercept between grain boundaries multiplied by 1.5 , was $0.35 \mu \mathrm{m}$. The grainboundary phase was examined by electron spectroscopy for chemical analysis (ESCA) and transmission electron microscopy (TEM) and found to contain $\mathrm{Cu}^{+}, \mathrm{Y}^{3+}, \mathrm{Zr}^{4+}$, and $\mathrm{O}^{2-}$ in a continuous amorphous layer of a thickness of 1 to $2 \mathrm{~nm}$. Deformation of this material was studied in compres-

\section{R. Raj-contributing editor}

\footnotetext{
Manuscript No. 198025. Received October 27, 1989; approved November $27,1989$.

Presented at 91st Annual Meeting of the American Ceramic Society, Indianapolis, IN, April 23-27, 1989 (Basic Science Division, Paper No. 124-B89).

Supported by the U.S. Air Force Office of Scientific Research under Grant No. 87-0289.

*Member, American Ceramic Society.
}

sion over a temperature range from $1000^{\circ}$ to $1250^{\circ} \mathrm{C}$ and found to be superplastic. At $1150^{\circ} \mathrm{C}$, the constitutive equation may be represented by

$$
Y=k \dot{\varepsilon}^{0.55}
$$

where $Y$ is the flow stress (MPa), $\dot{\varepsilon}$ is the strain rate $\left(\mathrm{s}^{-1}\right)$, and $k=2 \times 10^{3} \mathrm{MPa} \cdot \mathrm{s}^{0.55}$. Further details of the processing, characterization, and mechanical properties have been reported elsewhere. ${ }^{9}$

For superplastic forming, circular disks of a thickness of $1 \mathrm{~mm}$ and a diameter of $32 \mathrm{~mm}$ were prepared by grinding with diamond wheels. The surface roughness after grinding was measured by a surface roughness analyzer, and found to be of the order of $1 \mu \mathrm{m}$, primarily in the form of long grinding troughs and ridges. During forming, a disk was placed between a hemispherical punch and a circular die, both made of hot-pressed $\mathrm{SiC}$. The punch had a radius of $6 \mathrm{~mm}$ and the die inner diameter was $15.875 \mathrm{~mm}$ with a rounded edge. The edge of the disk was not clamped. After heating to $1150^{\circ}$ or $1200^{\circ} \mathrm{C}$ in air, the punch was advanced at a programmed displacement-time profile actuated by a servohydraulic mechanical tester.* Both constant displacement rate tests and constant strain rate tests, to be described later, were performed in this study. A typical experiment, forming a hatshaped article with a hemispherical dome, as shown in Fig. 1, was completed within $10 \mathrm{~min}$. The object had excellent surface finish and showed no wrinkling at the rim.

\section{Results and Discussion}

Load versus punch displacement curves for three runs are shown in Fig. 2, for $1150^{\circ}$ and $1200^{\circ} \mathrm{C}$, and for the constant punch speeds of 0.3 and $0.6 \mathrm{~mm} / \mathrm{min}$ (corresponding to a total forming time of 20 and $10 \mathrm{~min}$, respectively). The variation in the load can be qualitatively understood by the temperature and strain rate dependence of the flow stress and will be further analyzed later.

For a direct measurement of strains in the deformed region, several sets of Knoop indentation marks of various orientations were made on the outer surface before forming. These marks had a length of a few micrometers and a spacing of $250 \mu \mathrm{m}$. After forming, their locations were again measured from scanning electron microscopy (SEM) photographs and compared with the original sites. When combining these data with the profile of the deformed shell, we can calculate all the strain components, including radial strain $\varepsilon_{r}$, hoop strain $\varepsilon_{\theta}$, thickness strain $\varepsilon_{t}$, and effective strain $\varepsilon_{e}$, which is $\left[(2 / 3)\left(\varepsilon_{r}^{2}+\varepsilon_{\theta}^{2}+\varepsilon_{t}^{2}\right)\right]^{1 / 2}$. These results are shown in Fig. 3 . Two features of the strain distribution are notable. First, the punch contact region has a higher strain than that outside. Second, the maximum strain in the contact region is not located at the pole, but at $2 \mathrm{~mm}$ away from it. We also note that the flange was not deformed appreciably, as evidenced by the small decrease of the outer diameter after forming and its nearly unchanged thickness.

These results can be rationalized by the following picture of the stress states, schematically depicted in Fig. 4. In the 


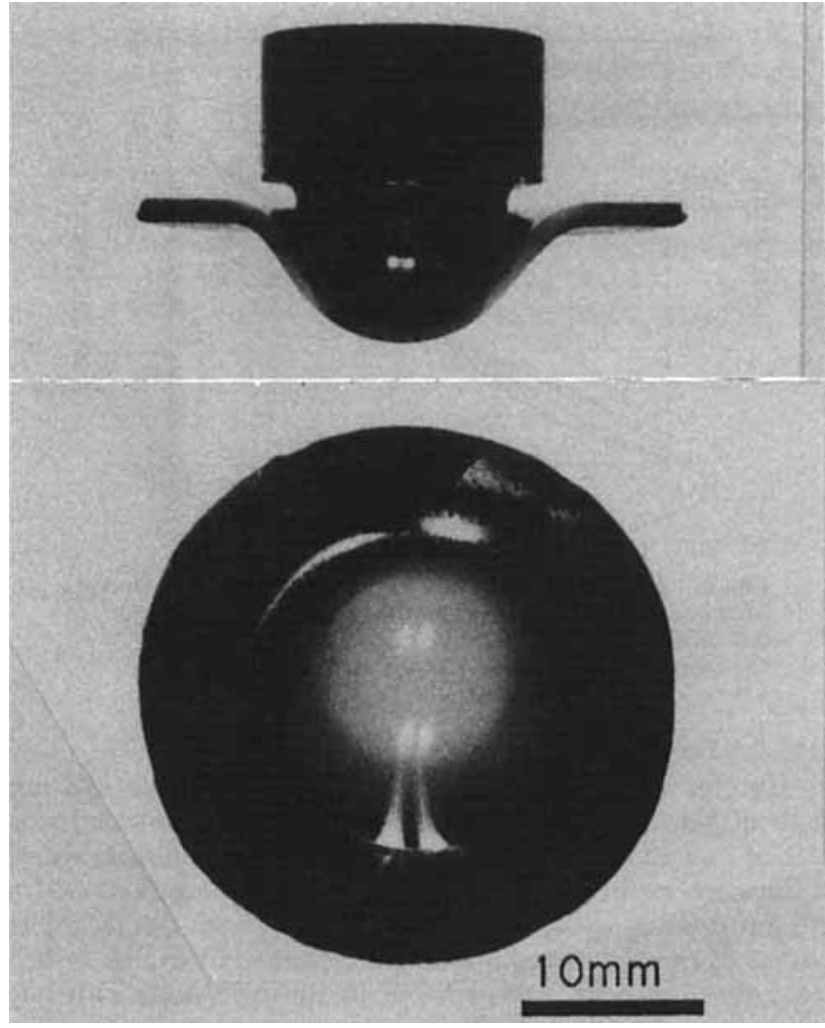

Fig. 1. $\mathrm{ZrO}_{2}$ sample after forming at $1150^{\circ} \mathrm{C}$ for $10 \mathrm{~min}$, with a constant punch velocity of $0.6 \mathrm{~mm} / \mathrm{min}$ (shown in top and side view, with the punch).

contact region, the stresses on the shell include a normal pressure from the die, a contact friction, and a biaxial tension in the shell. The above stress state causes a biaxial stretching of the shell, which also thins simultaneously. The friction reduces the biaxial tension, thus reducing the deformation at the pole. (This is commonly called the "friction hill" effect. ${ }^{10}$ ) Outside the contact region, the shell is deformed by a progressively smaller radial and hoop stress. Because of the lack of the normal pressure, the strain rate is now much lower, and a nearly stepwise drop in the strain rate is experienced at the edge of the punch contact region. Further outward, the hoop stress continues to decrease and eventually becomes compressive. Such compressive stress is mechanically required to support the net load of the punch. To be kinematically consistent, the hoop strain also becomes negative, made possible by the inward flow of the material from the region near

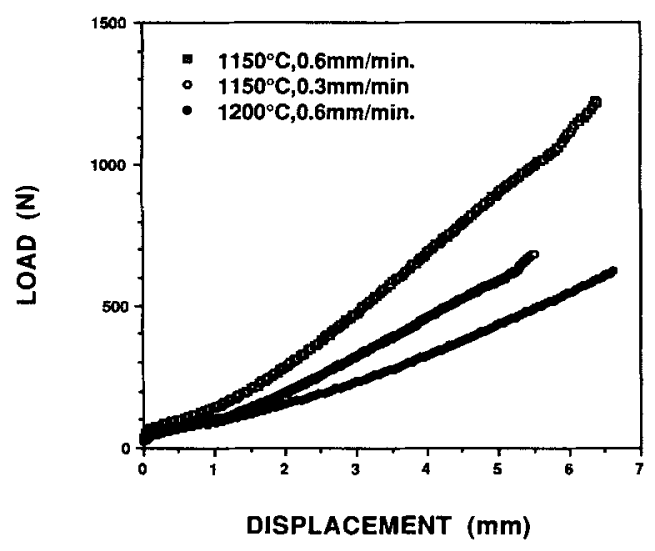

Fig. 2. Load-displacement curves for punch stretching at temperatures of $1150^{\circ}$ and $1200^{\circ} \mathrm{C}$, and at punch speeds of 0.3 and $0.6 \mathrm{~mm} / \mathrm{min}$.

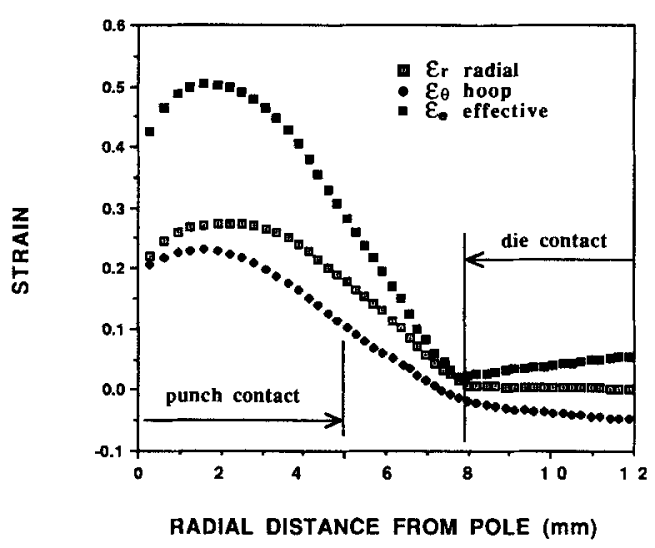

Fig. 3. Distribution of strains $\varepsilon_{r}, \varepsilon_{\theta}, \varepsilon_{e}$ over radial distance from pole.

the flange. It is now clear that in the present experiment, large strain biaxial tensile stretching, in a way quite similar to pressure bulging of a thin shell, has been achieved.

It is interesting to note that, although the present experiment has a configuration similar to deep drawing, ${ }^{10}$ in which the flange is under a minimum constraint, its mechanics actually resemble more that of punch stretching, ${ }^{10}$ in which the flange is clamped. In deep drawing, the thickness of the flange remains the same, but its diameter decreases so that the material is drawn inward toward the deepening wall; meanwhile, the base is not deformed. Thus the wall is under plane strain tension, but the flange is under plane strain shear. ${ }^{10}$ In the present experiment, however, owing to the lack of strain hardening in the superplastic regime, the material in contact with the punch, as well as the outer annulus in the dome, does not harden enough to transmit the requisite stress to draw in the flange. Rather, stretching and thinning

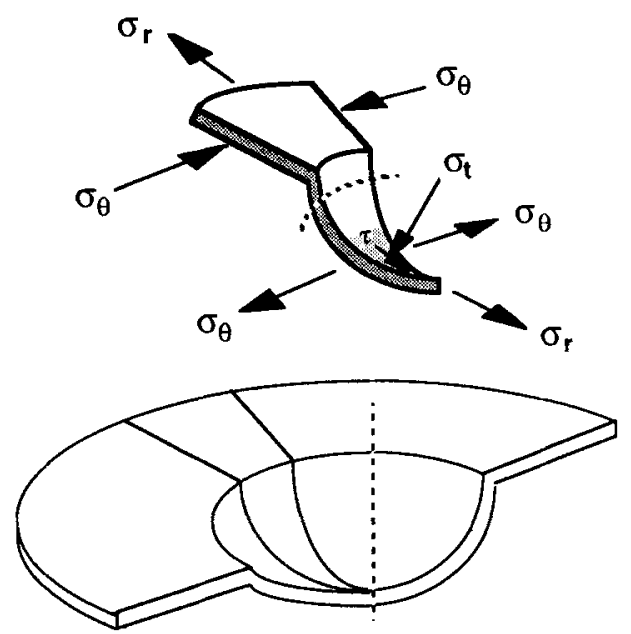

$\sigma$

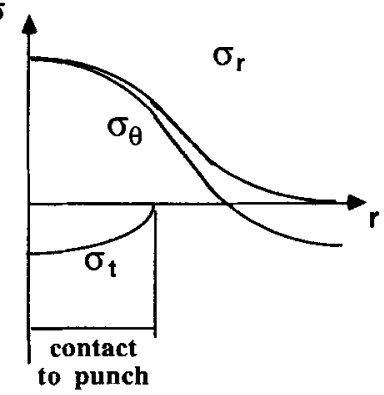

$\varepsilon$

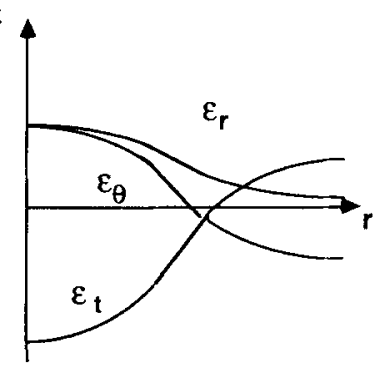

Fig. 4. Schematic of stress-strain states in punch stretching. 
are confined to the dome region inside the die lip in a way similar to punch stretching even though no hold-down is applied. ${ }^{10}$ In this connection it is important to note that, just like punch stretching, the present test of biaxial tensile stretching is much more severe than uniaxial tension. ${ }^{8}$ Thus, the large forming strains achieved by the present experiment is most assuring from a practical viewpoint concerning sheet ceramic forming.

At higher displacement rates or lower temperatures, fracture of the disk sometimes occurred when the punch displacement approached the end displacement of $6.5 \mathrm{~mm}$, as shown in Fig. 2. To determine the maximum strain rate reached prior to fracture, we have performed a simplified (upper bound) stress analysis assuming that the strain is uniform in the entire bulged region. From geometry, it can be shown that the area of the bulge $(A)$ is

$$
A=2 \pi R^{2}(1-\cos \beta)+\pi\left(a^{2}-R^{2} \sin ^{2} \beta\right) / \cos \beta
$$

where $R$ is the radius of the punch, $a$ is the inner radius of the die, and $\beta$ is the half angle subtended by the punch contact to the center of the punch. The height of the dome $(h)$ is given by

$$
h=R(1-\cos \beta-\sin \beta \tan \beta)+a \tan \beta
$$

Using the Tresca yield criterion, we find that the pressure required to deform the shell $(p)$ is

$$
p=2 Y \ln (1+t / R)
$$

where $t$ is the thickness of the shell. Then the total load on the punch $(P)$ is

$$
P=\pi R^{2} p \sin ^{2} \beta
$$

where the friction component has been ignored. Lastly, the strain rate is given by

$$
\dot{\varepsilon}=(\mathrm{d} A / \mathrm{d} \beta)(\mathrm{d} \beta / \mathrm{d} h)(\mathrm{d} h / \mathrm{d} t) / A
$$

where $\mathrm{d} h / \mathrm{d} t$ is the punch velocity. The above equations can be numerically evaluated to provide the load-displacement curves and the strain rate-displacement curves. These are shown in Fig. 5 for the deformation conditions given in Fig. 2. It is clear by comparing Figs. 2 and 5 that the predicted load-displacement curves are quite satisfactory, reproducing both qualitatively and quantitatively major features of the experimental results. It is seen that at a velocity of $0.6 \mathrm{~mm} / \mathrm{min}$, the strain rate has exceeded $10^{-3} \mathrm{~s}^{-1}$ when $h$ exceeded $5.5 \mathrm{~mm}$.

It is possible to avoid the strain rate maximum without lengthening the forming time by using a higher displacement rate initially and a lower one later. Indeed, the displacement

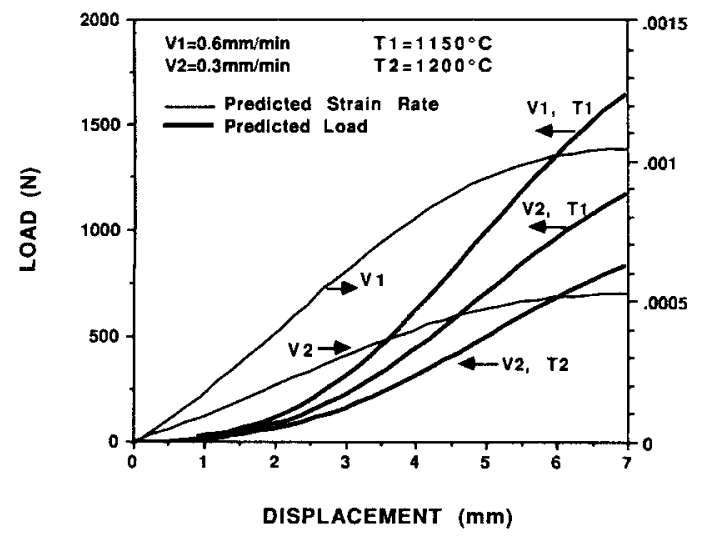

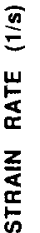

Fig. 5. Predicted load-displacement curves and strain rate-displacement curves for the experimental conditions in Fig. 2. The material flow properties taken from Hwang and Chen.

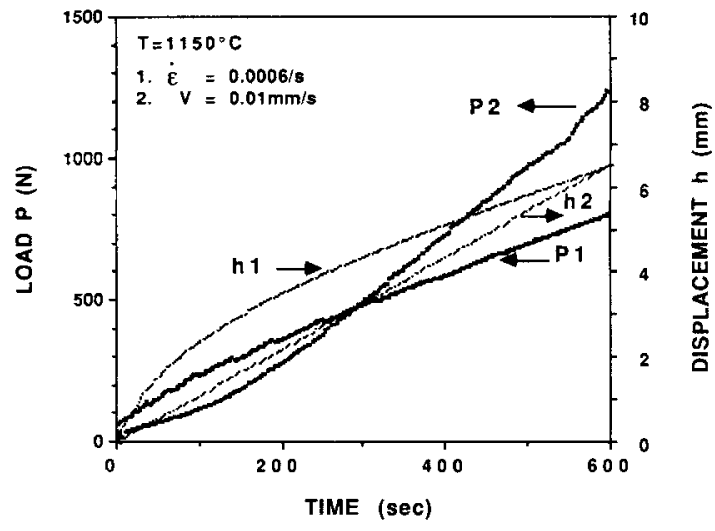

Fig. 6. Comparison of load and displacement in two forming schedules: (1) constant punch speed of $0.6 \mathrm{~mm} / \mathrm{min}$; (2) constant strain rate of $6 \times 10^{-3}$, with the same final shape at $10 \mathrm{~min}$.

rate can be programmed so that the average strain rate, given by Eq. (6), is a constant throughout the experiment. In one such displacement rate program, we used a constant strain rate of $6 \times 10^{-4} \mathrm{~s}^{-1}$ for a total forming time of $10 \mathrm{~min}$, which is the same as the total time if a constant displacement rate of $0.6 \mathrm{~mm} / \mathrm{min}$ is used. The recorded load and displacement curves of these two experiments are compared in Fig. 6. It is clear that the peak load is lower in the constant strain rate test than in the constant displacement test. Also, fracture was never encountered in the constant strain rate test at $1150^{\circ} \mathrm{C}$ when the forming time was $10 \mathrm{~min}$. Micrographic examinations of these specimens revealed a much better surface quality in all cases.

Surface damages were examined using SEM and found to accentuate at a distance of approximately $2 \mathrm{~mm}$ from the pole, in close agreement with the location of the maximum radial strain shown in Fig. 3. In cases where indentation marks were made, crack opening was always observed regardless of the orientation of the mark. This observation has provided a further confirmation of the biaxial tensile nature of the stresses in the contact region. Despite the opening, however, the indentation cracks did not seem to propagate. Instead, the continuous grinding marks tended to cause more severe cracking during forming and were responsible for shell fracture when it did take place. Some examples of surface cracking are shown in Fig. 7. These observations attest to the

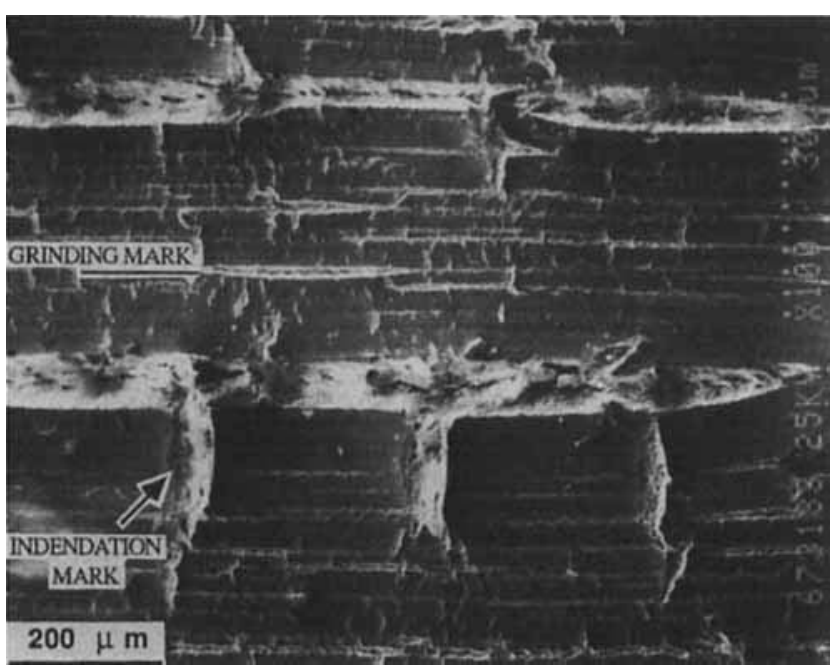

Fig. 7. Surface cracking after forming at $1150^{\circ} \mathrm{C}$ at $0.6 \mathrm{~mm} / \mathrm{min}$ the sample was ground and marked by Knoop indentation before forming. 
excellent damage tolerance of the superplastic TZP studied here. The higher propensity for damage development from long-dimension surface perturbations has been recognized in sheet-metal forming and analyzed previously. ${ }^{11-12}$ We also found that when the surface was prepolished using 1-mm diamond paste before forming, the population of surface cracking was greatly reduced.

\section{Conclusion}

We have demonstrated that superplastic forming in biaxial tension to large strains can be achieved in a fine-grained tetragonal zirconia, at $1150^{\circ} \mathrm{C}$, at a strain rate approaching $10^{-3} \mathrm{~s}^{-1}$. Mechanical analyses have been applied to rationalize the observed forming load, strain distribution and damages, and to suggest process modifications to improve forming condition. Given the excellent formability of this material, we believe that superplastic forming now provides an attractive alternative for near-net-shape forming of zirconia ceramics.

\section{References}

'B. J. Kellett and F.F. Lange, "Hot-Forging Characteristics of FineGrained $\mathrm{ZrO}_{2}$ and $\mathrm{Al}_{2} \mathrm{O}_{3} / \mathrm{ZrO}_{2}$ Ceramics," J. Am. Ceram. Soc., 69 [8] 172-73 (1986).

${ }^{2}$ F. Wakai, S. Sakaguchi, and H. Kato, "Compressive Deformation Proper- ties and Microstructures in the Superplastic Y-TZP,"J. Ceram. Soc. Jpn., 94 [8] 721-25 (1986)

${ }^{3} \mathrm{C}$. Carry and A. Mocellin, "Examples of Superplastic Forming FineGrained $\mathrm{Al}_{2} \mathrm{O}_{3}$ and $\mathrm{ZrO}_{2}$ Ceramics"; pp. 1043-52 in High Tech Ceramics, Materials Science Monograph 38A. Edited by P. Vincenzini, Elsevier, Amsterdam, Netherlands, 1987.

${ }^{4}$ F. Wakai, S. Sakaguchi, K. Kanayama, H. Kato, and H. Onishi, "Hot Work of Yttria-Stabilized Tetragonal $\mathrm{ZrO}_{2}$ Polycrystals"; pp. 315-22 in Ceramic Materials and Components for Engines. Edited by W. Bunk and $\mathrm{H}$. Hausner. Deutsch Keramische Gesellschaft, 1986.

${ }^{5} F$. Wakai, S. Sakaguchi, and Y. Matsuro, "Superplasticity of Yttria-Stabilized Tetragonal $\mathrm{ZrO}_{2}$ Polycrystals," Adv. Ceram. Mater., 1 [3] 259-63 (1986).

${ }^{6} \mathrm{~F}$. Wakai and $\mathrm{H}$. Kato, "Superplasticity of $\mathrm{TZP} / \mathrm{Al}_{2} \mathrm{O}_{3}$ Composite," Adv. Ceram. Mater., 3 [1] 71-76 (1988).

${ }^{7}$ T. G. Nieh, C. M. McNally, and J. Wadsworth, "Superplastic Properties of a Fine-Grained Yttria-Stabilized Tetragonal Polycrystal of Zirconia," Scr. Metall., 22 [8] 1297-1300 (1988).

${ }^{8}$ G. LeRoy and J. D. Embury, "The Utilization of Failure Maps to Compare the Fracture Modes Occurring in Aluminum Alloys"; pp. 183-207 in Formability. Edited by S.S. Hecker, A.F. Ghosh, and H.C. Gezel. The Metallurgical Society, AIME, New York, 1978.

${ }^{9}$ C. M. J. Hwang and I-W. Chen, "Effect of a Liquid Phase of Superplasticity of $2 \mathrm{~mol} \% \mathrm{Y}_{2} \mathrm{O}_{3}$-Stabilized Tetragonal Zirconia Polycrystals"; to be published in J. Am. Ceram. Soc.

${ }^{10}$ W. A. Backofen, Deformation Processing; pp, 162-68. Addison-Wesley, Reading, MA, 1972 .

${ }^{1} \mathrm{Z}$. Marciniak and K. Kuczynski, "Limit Strains in the Process of Stretch-Forming Sheet Metal," Int. J. Mech. Sci., 9, 609-20 (1967).

${ }^{12}$ K. Neglo, E. Chater, and K.W. Neale, "Effects of the Shape of a Geometric Defect and of Interactions Between Defects of Limit Strains for Biaxially Stretched Sheets," Int. J. Mech. Sci., 29 [12] 807-20 (1987). 